\title{
UVA "NIÁGARA ROSADA" CULTIVADA NO SISTEMA ORGÂNICO E ARMAZENADA EM DIFERENTES TEMPERATURAS
}

\author{
Alessandra M. DETONI', Edmar CLEMENTE", Gilberto Costa BRAGA', Neuza Francisca M. HERZOG
}

\section{RESUMO}

O sistema de cultivo, as cultivares, as condições de colheita e pós-colheita têm efeito direto na conservação e qualidade das uvas. Diante disso, este trabalho objetivou avaliar o efeito do tempo $(0,7,14,21,28$ e 35 dias) e da temperatura de armazenamento (1, 14 e $24^{\circ} \mathrm{C}$ ) na qualidade pós-colheita da uva "Niágara Rosada" cultivada no sistema orgânico. O fator limitante para o armazenamento foi o elevado índice de degrana, porém, as uvas ainda possuíam qualidade para o consumo, por observar a manutenção do teor de sólidos solúveis totais, acidez total titulável e pH. Dentre as avaliações químicas, o teor de sólidos solúveis totais, a acidez total titulável e o teor de vitamina $\mathrm{C}$ foram as únicas variáveis que apresentaram diminuição acentuada para as frutas armazenadas a $24^{\circ} \mathrm{C}$, resultando em um curto período de armazenamento. As frutas armazenadas a $14^{\circ} \mathrm{C}$ não apresentaram grandes variações nas características químicas, mantendo uma boa qualidade para o consumo por até 28 dias de armazenamento. A melhor temperatura para a conservação das frutas foi $1^{\circ} \mathrm{C}$, em que as uvas alcançaram 35 dias de armazenamento sem grande variação na qualidade para o consumo.

Palavras-chave: uva; sistema orgânico; armazenamento; temperatura.

\section{SUMMARY}

"NIÁGARA ROSADA" GRAPES CULTIVATED UNDER ORGANIC SYSTEM AND STORED AT DIFFERENT TEMPERATURES. The cultivation system, the cultivars, the crop conditions and post harvest, can effect the conservation and quality of the grapes. This work aimed the evaluation of the affect of the time of storage $(0,7,14,21,28$ and 35 days) and the storage temperature $(1,14$ and $24^{\circ} \mathrm{C}$ ) in the quality of the grape "Niágara Rosada" pots harvest cultivated in the organic system. The limiting point for the storage was the high number of free berries observed, however the grapes still have quality for consumption, because observing without modification in the tenor of total soluble, the total titratable acidity and $\mathrm{pH}$. Among the chemical assay, the determination of the tenor of total soluble solids, the total titratable acidity and the vitamin tenor $\mathrm{C}$ were the only ones which presented a decrease accentuated for the fruits stored at $24^{\circ} \mathrm{C}$, in a lower period of storage. The fruits stored at $14^{\circ} \mathrm{C}$ up to 28 days did not show higher changes in their chemical characteristics and the grapes still have consumption quality and also for use in food industry. The best temperature of storage was $1^{\circ} \mathrm{C}$ when grapes achieved 35 days with good quality.

Keywords: grape; organic system; storage; temperature.

\section{1 - INTRODUÇÃO}

A uva "Niágara Rosada" apresenta-se como uma das principais uvas consumidas no Brasil, por ter alta qualidade para o consumo in natura, bem como ao baixo custo de produção, o que tem permitido grande expansão na área cultivada [8]. Dentre as cultivares de mesa, a "Niágara Rosada"' destaca-se como uma das preferidas do paladar brasileiro, embora classificada como comum. Esta cultivar apresenta sabor característico muito apreciado pelo consumidor, sendo que a polpa desprende-se facilmente da película, quando a baga é pressionada [5].

No mercado de frutas frescas, o consumidor está cada dia mais preocupado com a origem dos produtos que vai adquirir, com a presença de resíduos tóxicos e a conservação da fruta. Dessa forma, o consumo de produtos orgânicos tem aumentado a cada dia, o que induz mudanças na produção, no armazenamento, distribuição e comercialização de produtos agrícolas [15]. Essa cons-

Recebido para publicação em 03/12/2004. Aceito para publicação em 25/07/2005(001451).

Programa de Pós-Graduação em Agronomia,Universidade Estadual de Maringá (UEM). Endereço: Av. Colombo, 5790, CEP: 87020-900, Maringá-PR. E-mail: eclemente@uem.br

Curso de Agronomia, Universidade Estadual do Oeste do Paraná Endereço: Rua Pernambuco, 1777, CEP: 85960-000, Campus de Marechal Cândido Rondon-PR.

L Laboratório de Tecnologia de Alimentos, Universidade Estadual do Oeste do Paraná.

A quem a correspondência deve ser enviada. ciência ecológica converte-se em uma oportunidade para a agricultura, valorizando o comércio de produtos orgânicos, levando alguns viticultores a direcionar a produção tradicional para a produção orgânica ou integrada.

A uva "Niágara Rosada", juntamente com a "Isabel", são destaques como uvas de mesa comuns. São variedades rústicas menos exigentes em tratos culturais e, por serem mais tolerantes às doenças fúngicas, estão bem adaptadas às condições de clima úmido [20], podendo ser cultivada no sistema orgânico, onde não são realizadas aplicações de defensivos químicos.

Diante disso, este trabalho objetivou avaliar algumas características físicas e químicas da uva "Niágara Rosada" cultivada no sistema orgânico e armazenada em diferentes temperaturas.

\section{2 - MATERIAL E MÉTODOS}

\section{1 - Material}

Foram utilizadas uvas "Niágara Rosada" cultivadas em pomar comercial no municipio de ToledoPR, situado a $547 \mathrm{~m}$ de altitude, latitude sul $24^{\circ} 45^{\prime}$ e longitude oeste 534' [22]. O pomar é conduzido no sistema orgânico, com certificado expedido pelo Instituto Biodinâmico de Desenvolvimento Rural (IBD).

Após a colheita, os cachos foram selecionados quanto à cor e ausência de defeitos (bagas danificadas, deterioradas, com má formação, cachos muito pequenos) e 
acondicionados em caixas de papelão microondulado, com capacidade para $2,5 \mathrm{Kg}$, possuindo 4 orificios frontais e 6 nas laterais. Posteriormente, as caixas foram envolvidas com filme plástico de PVC ( $13 \mu \mathrm{m}$ de espessura).

Após o acondicionamento das uvas nas caixas de papelão microondulado, as mesmas foram dispostas em câmaras B.O.D., previamente lavadas e esterilizadas e posteriormente reguladas a $1^{\circ} \mathrm{C}, 14^{\circ} \mathrm{C}$ e $24^{\circ} \mathrm{C}\left( \pm 2^{\circ} \mathrm{C}\right)$ e umidade relativa em torno de $85-90 \%$, mantida através de lâmina de água, sendo monitorada por higrômetro periodicamente.

\section{2 - Delineamento experimental}

O delineamento experimental utilizado foi o inteiramente casualizado e as determinações físicas e químicas foram realizadas em função do período $(0,7,14,21,28$ e 35 dias) e temperatura $\left(1,14\right.$ e $\left.24^{\circ} \mathrm{C}\right)$ de armazenamento das uvas. A amostra global foi subdividida em dois grupos, de modo a possibilitar o estudo dos parâmetros físicos e químicos separadamente, com base nos mesmos fatores experimentais (tempo e temperatura).

Para as determinações fisicas, as parcelas experimentais foram compostas de doze cachos de uva por caixa, num total de quatro repetições (caixas) por temperatura. As caixas e os cachos de uva foram devidamente etiquetados, sendo cada cacho avaliado semanalmente durante o período de armazenamento.

Para as determinações químicas, as unidades experimentais foram montadas com base no mesmo planejamento utilizado para as físicas, porém com dez cachos de uva por caixa para cada semana de avaliação.

\section{3 - Determinações físicas}

As determinações fisicas realizadas foram: índice de degrana e qualidade do engaço.

O índice de degrana foi calculado em percentagem (\%), tomando-se por base o número de bagas caídas a cada avaliação em relação ao número total de bagas do cacho. A qualidade do engaço foi avaliada visualmente através da comparação do aspecto do engaço com uma escala descrita por CASTRO [7] onde: 1-Verdes, túrgidos, com aspecto de recém-colhido, 2-Verdes e levemente secos (verde opaco), 3-Verde com pontuações marrons, levemente secos, 4-Marrons, secos e 5-Marrons, muito secos, quebradiços. Estabelecendo-se a classificação 3 como limite de aceitação para a comercialização.

\section{4 - Determinações físico-químicas e enzimáticas}

As análises físico-químicas realizadas foram: o teor de sólidos solúveis totais, acidez total titulável, $\mathrm{pH}$, teor de ácido ascórbico e a atividade enzimática da polifenoloxidase e peroxidase.

O teor de sólidos solúveis totais foi determinado por refratometria, através de refratômetro marca Cosmo, Tipo K-32, de acordo com normas da AOAC [2].
Acidez total titulável: $10 \mathrm{~mL}$ de suco foram transferidos para balão volumétrico de $100 \mathrm{~mL}$ e o volume completado com água destilada. Esta solução foi titulada com solução padrão de hidróxido de sódio $0,1 \mathrm{M}$ de acordo com metodologia descrita pelo INSTITUTO DE TECNOLOGIA DE ALIMENTOS [18].

$\mathrm{O} \mathrm{pH}$ foi determinado em amostra composta por polpa+semente, utilizando-se pHmetro digital marca Digimed, modelo D.M. - 20. Os resultados foram expressos em unidades de $\mathrm{pH}$ [2].

A determinação do ácido ascórbico baseou-se na redução do 2,6-diclorofenolindofenol-sódio pelo ácido ascórbico. Para isto adicionou-se $5 \mathrm{~mL}$ de suco de uva em erlenmeyer com $50 \mathrm{~mL}$ de ácido oxálico $1 \%$. Posteriormente, titulou-se (suco de uva+ácido oxálico $1 \%$ ) com solução de 2,6-diclorofenolindofenol $0,2 \%$ até coloração rosa persistente por $15 \mathrm{~min}$. Os teores de ácido ascórbico das amostras foram calculados tomando-se por base um padrão previamente determinado. Os resultados foram expressos em $\mathrm{mg}$ de ácido ascórbico por $100 \mathrm{~mL}$ de suco, de acordo com o método titulométrico de Tillmans, modificado pelo INSTITUTO DE TECNOLOGIA DE ALIMENTOS [18].

Atividade da peroxidase: primeiramente procedeuse a obtenção do extrato enzimático da uva, 100g de uva foram lavadas em água destilada e homogeneizadas em liquidificador com $50 \mathrm{~mL}$ de solução tampão fosfato de sódio $100 \mathrm{mM}$, pH 6,0 e $1 \%$ de polivinilpirrolidona. Em seguida, o homogeneizado foi filtrado em tecido de algodão e recolhido em Becker em banho de gelo. Este filtrado foi centrifugado a $4000 \mathrm{rpm}$ durante $20 \mathrm{~min}$ a $4^{\circ} \mathrm{C}$. Ao sobrenadante designou-se extrato enzimático de uva.

Na determinação da atividade de peroxidase tomouse $0,2 \mathrm{~mL}$ do extrato enzimático e adicionou-se $2,7 \mathrm{~mL}$ de solução de peróxido de hidrogênio $(0,03 \%$ em tampão fosfato de sódio $100 \mathrm{mM} \mathrm{pH} \mathrm{6,0).} \mathrm{A} \mathrm{reação} \mathrm{enzimática} \mathrm{te-}$ ve início quando foi adicionado $0,1 \mathrm{~mL}$ de solução de o-dianisidina (solução alcoólica 1\% p/v). Em seguida fezse a leitura da absorbância a 460nm, em espectrofotômetro UV/Visivel por $1 \mathrm{~min}$. Os resultados foram expressos em unidades de peroxidase por minuto por $100 \mathrm{~mL}$ de suco. A peroxidase foi determinada segundo o método descrito por CLEMENTE [11].

A atividade da polifenoloxidase: em $0,5 \mathrm{~mL}$ do extrato enzimático de uva adicionou-se $1,8 \mathrm{~mL}$ de tampão fosfato de sódio $100 \mathrm{mM}, \mathrm{pH} 6,0$ e $0,05 \mathrm{~mL}$ de catecol $10 \mathrm{mM}$. Esta mistura foi aquecida a $30^{\circ} \mathrm{C}$ por 30 minutos. Após este período foi adicionado $0,8 \mathrm{~mL}$ de ácido perclórico $2 \mathrm{M}$ e colocada em banho de gelo.

Em seguida fez-se a leitura da absorbância a 395nm, em espectrofotômetro UV/Visivel, e os resultados foram expressos em unidade de polifenoloxidase por minuto por $100 \mathrm{~mL}$ de suco. A determinação da enzima polifenoloxidase foi realizada de acordo com metodologia proposta por JANOVITZ-KLAPP, RICHARD \& NICOLAS [19]. 


\section{5 - Análise estatística}

Para cada temperatura as variáveis foram analisadas em função do periodo de armazenamento, através da análise de regressão, utilizando-se o pacote estatístico SAEG [25]. Para os valores em percentagem os dados originais foram transformados em arco sen $\sqrt{\frac{x}{100}}$ [16].

\section{3 - RESULTADOS E DISCUSSÃO}

\section{1 - Determinações físicas}

Cada temperatura proporcionou um período distinto de armazenamento, sendo que na temperatura de $1^{\circ} \mathrm{C}$ os frutos puderam ser avaliados até o $35^{\circ}$ dia, no armazenamento a $14^{\circ} \mathrm{C}$ até o $28^{\circ}$ dia e na temperatura de $24^{\circ} \mathrm{C}$ até $21^{\circ}$ dia de armazenamento.

Na Figura 1 pode-se observar que quando armazenadas a $1^{\circ} \mathrm{C}$ o indice de degrana das uvas permaneceu sem grandes alterações até o $14^{\circ}$ dia de armazenamento. Porém, após a terceira semana este índice aumentou de forma mais acentuada, chegando a $65 \%$ de degrana ao $35^{\circ}$ dia.

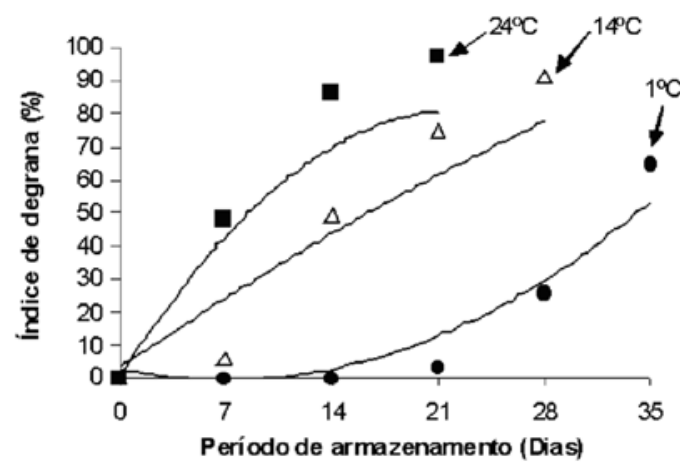

FIGURA 1 - Îndice de degrana (\%) de uvas "Niágara Rosada", cultivadas no sistema orgânico e armazenadas a $1^{\circ} \mathrm{C} \quad\left(\mathrm{y}=0,0687 \mathrm{x}^{2}-0,9615 \mathrm{x}+2,6917, \mathrm{R}^{2}=0,9962^{*}\right), 14^{\circ} \mathrm{C}$ $\left(y=-0,0418017 x^{2}+4,0580 x-4,09772, R^{2}=0,96^{*}\right)$ e $24^{\circ} \mathrm{C}$ $\left.9 y=-0,1612 x+7,2184 x+0,261, R^{2}=1^{*}\right) \cdot{ }^{*} P<0,05$

Apesar de apresentar elevado índice de degrana ao $35^{\circ}$ dia de armazenamento a $1^{\circ} \mathrm{C}$ (Figura 1), as uvas ainda possuíam qualidade para o consumo, observando-se a manutenção do teor de sólidos solúveis totais, acidez total titulável e $\mathrm{pH}$ ao final deste período, como pode ser constatado no item 3.2. VALENTINI \& MIQUELETTO [26] ao avaliar a conservação de uva "Niágara" (Vitis labrusca) sob armazenamento refrigerado a $1^{\circ} \mathrm{C}$ observaram que esta temperatura proporcionou a conservação das uvas por 28 dias, com reduzida porcentagem de degrana e perda de peso.

Verificou-se grande diferença no índice de degrana, durante a segunda semana de armazenamento, comparando-se as temperaturas de $1^{\circ} \mathrm{C}$ e $14^{\circ} \mathrm{C}$ (Figura 1), com valores de $0,25 \%$ e $49,5 \%$ de degrana, respectivamente. Demonstrando que ocorreu um aumento na percentagem de degrana com o aumento da temperatura. Estes dados são semelhantes aos obtidos com uvas da variedade Isabel [13], cultivadas em sistema convencional, onde temperaturas mais baixas de armazenamento $(-0,3$ e $1,0^{\circ} \mathrm{C}$ ) proporcionaram maior resistência a degrana que em temperaturas mais elevadas $\left(0^{\circ} \mathrm{C}\right)$.

As bagas, armazenadas a $14^{\circ} \mathrm{C}$, apresentavam pouco aspecto de murchamento, porém, observou-se elevado escurecimento e secagem do engaço, decorrentes da desidratação, fator que provavelmente favoreceu a elevada porcentagem de degrana (Figura 1) e conseqüentemente elevados indices de perda de massa. De acordo com BRACKMANN, MAZARO \& WACLAWOVSKY [3] o escurecimento do engaço está relacionado com a desidratação.

No $7^{\circ}$ dia de armazenamento a $24^{\circ} \mathrm{C}$ observou-se elevado índice de degrana, cuja perda de bagas foi de aproximadamente $48 \%$ (Figura 1). No entanto, neste periodo o teor de sólidos solúveis totais e a acidez total titulável (item 3.2) não apresentaram grandes variações em relação aos teores iniciais. Demonstrando manutenção da qualidade da uva, porém, com perdas a nível econômico devido à perda de massa decorrente do elevado índice de degrana. CENCI [8] ao avaliar o armazenamento de uva "Niágara Rosada" sob temperatura ambiente, também constatou que esta temperatura possibilita uma vida útil aos frutos de apenas 7,5 dias.

O mesmo foi verificado por VALENTINI \& MIQUELETTO [26] ao avaliar a conservação de uva "Niágara" (Vitis labrusca) em condição ambiente, os quais recomendam um período máximo de armazenamento de sete dias, relatando que os fatores críticos para a conservação foram a degrana e a perda de peso.

A qualidade do engaço é fator muito importante na determinação da conservação das uvas. Engaços escurecidos e secos depreciam a qualidade das uvas para comercialização e também proporcionam maior índice de degrana. Neste experimento verificou-se que nas amostras de uva armazenadas a $1^{\circ} \mathrm{C}$ (Figura 2) a qualidade do engaço permaneceu na classificação 3 da escala (limite de aceitação para a comercialização) até a terceira semana de armazenamento, demonstrando que nesta temperatura a qualidade do engaço permaneceu adequada para o comércio até este período.

Após a quarta semana a qualidade do engaço passou para a classificação 4 (Marrons, secos). Semelhante ao verificado por CASTRO [7] que ao avaliar a qualidade do engaço de uva "Itália" armazenada a $3^{\circ} \mathrm{C}$ não observou diferenças significativas da segunda a quarta semana de armazenamento, a partir da quarta semana os engaços de apresentavam verde opacos, com pontuações marrons. Isto pode ser um indicativo de que a vida útil pós-colheita da uva, pode ser avaliada com base na qualidade do engaço a temperaturas de armazenamento entre 1 e $3^{\circ} \mathrm{C}$. 


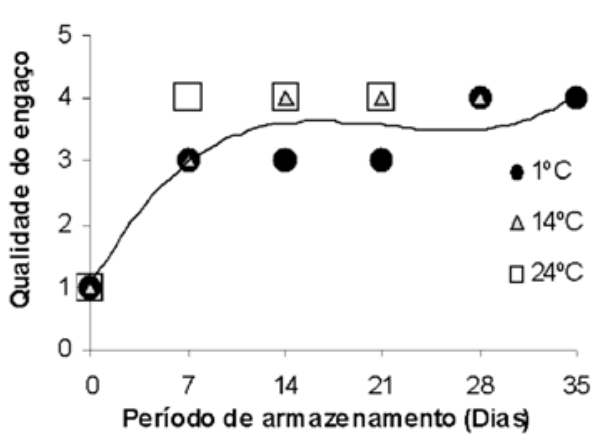

FIGURA 2 - Qualidade do engaço de uvas "Niágara Rosada", cultivadas no sistema orgânico e armazenadas a $1^{\circ} \mathrm{C}$ $\left(\mathrm{y}=0,0003 \mathrm{x}^{3}-0,0202 \mathrm{x}^{2}+0,4057 \mathrm{x}+1,0218, \quad \mathrm{R}^{2}=0,97^{*}\right), \quad 14^{\circ} \mathrm{C}$ $\left(y=3,2^{\prime \prime}\right)$ e $24^{\circ} \mathrm{C}\left(\mathrm{y}=3^{n * *}\right) \cdot{ }^{*} \mathrm{P}<0,05$

Em relação às amostras mantidas a $14^{\circ} \mathrm{C}$ e $24^{\circ} \mathrm{C}(\mathrm{Fi}$ gura 2) não foram observadas diferenças significativas $(\mathrm{P}>0,05)$ na qualidade do engaço em relação às semanas de armazenamento. Observou-se que na segunda semana o engaço já estava marrom seco. O aspecto do engaço marrom seco observado no armazenamento a 14 e $24^{\circ} \mathrm{C}$ pode ter sido favorecido pela temperatura mais elevada.

\section{2 - Determinações físico-químicas e enzimáticas}

Nas uvas armazenadas a $1^{\circ} \mathrm{C}$ o teor da acidez total titulável (ATT) não apresentou diferenças significativas $(\mathrm{P}>0,05)$ durante o período de armazenamento (Figura 3), com valores variando de 0,64 a $0,70 \mathrm{~g}$ de ácido tartárico. $100 \mathrm{~mL}^{-1}$ de suco. No armazenamento a $14^{\circ} \mathrm{C}$ o teor da ATT também não apresentou diferenças significativas, apresentando uma variação de 0,60 a 0,64g de ácido tartárico. $100 \mathrm{~mL}$ de suco (Figura 3). A manutenção dos teores de ATT pode ser um indicativo de que nestas temperaturas o metabolismo permaneceu quase inalterado, ou com pequenas transformações, porém sem causar grandes variações nos resultados.

De acordo com YAMASHITA et al. [30] a manutenção das características da uva ao longo do armazenamento pode ser justificada devido ao padrão respiratório nãoclimatérico. GRANGEIRO et al. [17] ao avaliar a conservação de uvas Superior Seedles submetidas ao armazenamento refrigerado, verificaram que o teor de acidez total titulável (ATT) se manteve inalterado durante o armazenamento. Os autores atribuíram a manutenção da ATT ao padrão respiratório não-climatérico característico da uva.

As amostras armazenadas a $24^{\circ} \mathrm{C}$ apresentaram um decréscimo significativo $(\mathrm{P}<0,05)$ no teor da ATT, de $0,64 \mathrm{~g}$ de ácido tartárico. $100 \mathrm{~mL}$ no início do experimento para $0,53 \mathrm{~g}$ de ácido tartárico. $100 \mathrm{~mL}$ ao final do armazenamento (Figura 3). CENCI [8] não verificou diminuição no teor de ATT em uvas "Niágara Rosada" armazenadas a $24^{\circ} \mathrm{C}$. Segundo o mesmo autor as uvas apresenta-

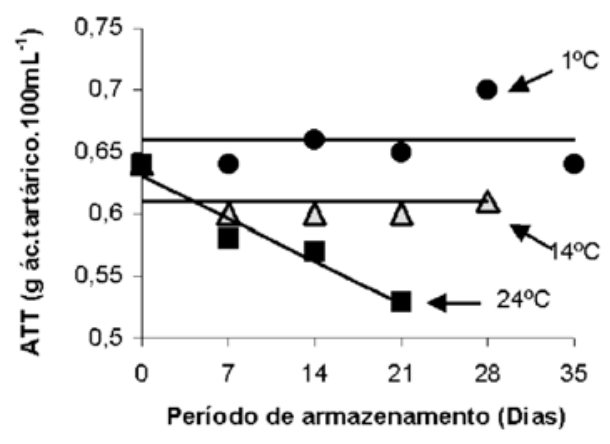

FIGURA 3 - Acidez total titulável (g de ácido tartárico100mL ) de uvas "Niágara rosada", cultivadas no sistema orgânico e armazenada a $1^{\circ} \mathrm{C}\left(\mathrm{y}=0,66^{\mathrm{n}}\right), 14^{\circ} \mathrm{C}\left(\mathrm{y}=0,61^{\mathrm{n}}\right)$ e $24^{\circ} \mathrm{C}$ $\left(y=-0,0049 x+0,6308, R^{2}=0,90^{*}\right) .{ }^{*} P<0,05$

ram em média 0,$70 ; 0,83 ; 0,83 ; 0,85$ e $0,83 g$ de ácido tartárico. $100 \mathrm{~mL}$ para $0 ; 2,5 ; 5,0 ; 7,5$ e 10 dias após a colheita, respectivamente.

Após a colheita, o teor de ácidos orgânicos pode sofrer alterações, pois um aumento na respiração pode ocasionar a degradação oxidativa de alguns componentes da polpa. A diminuição da ATT no final do período de armazenamento a $24^{\circ} \mathrm{C}$ (Figura 3) pode ser decorrente desta degradação oxidativa. Para RUFFNER, BREM \& MALIPIERO [24] e AL KAISY et al. [1], os ácidos orgânicos estão entre os principais substratos de respiração da uva. Esta taxa de respiração depende, dentre alguns fatores, da temperatura de armazenamento, consistindo na degradação de substâncias como polissacarídeos, açúcares simples, ácidos orgânicos, proteínas e lipídios [28].

$\mathrm{Na}$ avaliação do $\mathrm{pH}$ foram observadas pequenas alterações durante o período de armazenamento nas três temperaturas $\left(1^{\circ} \mathrm{C}, 14^{\circ} \mathrm{C}\right.$ e $\left.24^{\circ} \mathrm{C}\right)$, de modo que apesar das variações ocorridas ao longo do período (Tabela 1), ao final do experimento os frutos apresentaram aproximadamente os mesmos valores de $\mathrm{pH}$ verificados no início do armazenamento.

TABELA 1 - Valores médios de pH de uvas "Niágara Rosada", cultivada no sistema orgânico e armazenadas a $1^{\circ} \mathrm{C}, 14^{\circ} \mathrm{C}$ e $24^{\circ} \mathrm{C}$

\begin{tabular}{ccccccc}
\hline & \multicolumn{5}{c}{ Temperatura de armazenamento $\left({ }^{\circ} \mathrm{C}\right.$ ) } \\
\hline $\begin{array}{c}\text { Periodo de } \\
\text { armazenamento } \\
\text { (Dias) }\end{array}$ & \multicolumn{2}{c}{$1^{\circ} \mathrm{C}$} & \multicolumn{2}{c}{$14^{\circ} \mathrm{C}$} & \multicolumn{2}{c}{$24^{\circ} \mathrm{C}$} \\
\cline { 2 - 7 } & $\mathrm{pH}^{*}$ & $\delta$ & $\mathrm{pH}^{*}$ & $\delta$ & $\mathrm{pH}^{*}$ & $\delta$ \\
\hline 0 & 2,92 & $\pm 0,048$ & 2,92 & $\pm 0,048$ & 2,92 & $\pm 0,048$ \\
7 & 2,99 & $\pm 0,036$ & 3,12 & $\pm 0,055$ & 3,28 & $\pm 0,023$ \\
14 & 2,98 & $\pm 0,042$ & 2,87 & $\pm 0,058$ & 2,92 & $\pm 0,019$ \\
21 & 2,93 & $\pm 0,031$ & 2,91 & $\pm 0,22$ & 3,11 & $\pm 0,057$ \\
28 & 3,50 & $\pm 0,022$ & 3,72 & $\pm 0,18$ & $(-)$ & $(-)$ \\
35 & 2,90 & $\pm 0,034$ & $(-)$ & $(-)$ & $(-)$ & $(-)$ \\
\hline 3 repetiçōes & & & & & &
\end{tabular}

CENCI [8] trabalhando com armazenamento de uva "Niágara Rosada", também obteve pequenas diferenças entre as médias de $\mathrm{pH}$, não permitindo conclusões. Para CHITARRA \& CHITARRA [9] a capacidade tampão de al- 
guns sucos permite que ocorram variações na ATT, sem alterações apreciáveis no $\mathrm{pH}$.

Os resultados verificados para o $\mathrm{pH}$ das uvas orgânicas durante o período de armazenamento estão de acordo com os dados obtidos por FERREIRA [14] e ORLANDO [23] ao avaliar o pH de uvas "Niágara Rosada" cultivadas convencionalmente, os quais verificaram 3,35 e 3,10 unidades de $\mathrm{pH}$, respectivamente.

Em relação ao teor de sólidos solúveis totais (SST) não foram observadas diferenças significativas $(\mathrm{P}>0,05)$ durante as semanas de armazenamento a $1^{\circ} \mathrm{C}$ e $14^{\circ} \mathrm{C}(\mathrm{Fi}$ gura 4). Ambas temperaturas apresentaram uma média de SST de $16,27^{\circ}$ Brix durante o período.

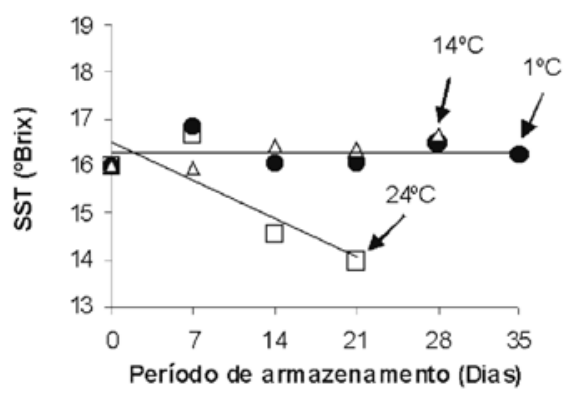

FIGURA 4 - Teor médio de sólidos solúveis totais ( $\left.{ }^{\circ} \mathrm{Brix}\right)$ de uvas "Niágara Rosada"', cultivadas no sistema orgânico e armazenadas a $1^{\circ} \mathrm{C}\left(\mathrm{y}=16,27^{\circ \prime}\right), 14^{\circ} \mathrm{C}\left(\mathrm{y}=16,27^{\circ \prime}\right)$ e $24^{\circ} \mathrm{C}$ $\left(y=-0,1183 x+16,542, R=0,71^{*}\right) .{ }^{*} P<0,05$

No armazenamento a $24^{\circ} \mathrm{C}$ os SST decresceram $(\mathrm{P}<0,05)$ durante o armazenamento, de $16^{\circ}$ Brix na primeira avaliação para $13,96^{\circ}$ Brix na última (Figura 4). De acordo com COOMBE [12] este decréscimo no teor de SST está associado a utilização dos açúcares como substratos na atividade respiratória.

Na Tabela 2 podemos verificar que o teor de vitamina $\mathrm{C}$ apresentou decréscimo ao final do período de armazenamento nas três temperaturas. No armazenamento a $1^{\circ} \mathrm{C}$ ao $28^{\circ}$ dia, os frutos continham aproximadamente $79,3 \%$ do teor inicial de vitamina C. Ao $21^{\circ}$ dia de armazenamento a $14^{\circ} \mathrm{C}$ o conteúdo de vitamina $\mathrm{C}$ era de aproximadamente $58,9 \%$ do conteúdo inicial (Tabela 2), demonstrando que esta variável pode ser um bom parâmetro para acompanhar a vida útil pós-colheita, de modo que até o $28^{\circ}$ e $21^{\circ}$ dias de armazenamento a 1 e $14^{\circ} \mathrm{C}$, respectivamente, as uvas ainda apresentavam boas condições para a comercialização.

Nas amostras armazenadas a $24^{\circ} \mathrm{C}$ o teor de vitamina $\mathrm{C}$ aos vinte e um dias era de aproximadamente $71,9 \%$ do valor inicial (Tabela 2). CARDELLO \& CARDELLO [6] citam que a determinação do conteúdo de ácido ascórbico em vegetais é importante, pois, sendo a vitamina mais termolábil, sua presença no alimento indica que provavelmente os demais nutrientes também estão sendo preservados.
TABELA 2 - Valores médios de vitamina C (mg de ácido ascórbico.100mL ) de uvas "Niágara Rosada", cultivadas no sistema orgânico e armazenadas a $1^{\circ} \mathrm{C}, 14^{\circ} \mathrm{C}$ e $24^{\circ} \mathrm{C}$, durante 35,28 e 21 dias, respectivamente.

\begin{tabular}{|c|c|c|c|c|c|c|}
\hline \multirow{3}{*}{$\begin{array}{c}\text { Periodo de } \\
\text { armazenamento } \\
\text { (Dias) }\end{array}$} & \multicolumn{6}{|c|}{ Temperatura de armazenamento $\left({ }^{\circ} \mathrm{C}\right)$} \\
\hline & \multicolumn{2}{|c|}{$1^{\circ} \mathrm{C}$} & \multicolumn{2}{|c|}{$14^{\circ} \mathrm{C}$} & \multicolumn{2}{|c|}{$24^{\circ} \mathrm{C}$} \\
\hline & Vit. $\mathrm{C}^{\star}$ & $\delta$ & Vit. $\mathrm{C}^{*}$ & $\delta$ & Vit. $\mathrm{C}^{*}$ & $\delta$ \\
\hline 0 & $\begin{array}{c}0,92 \\
(100 \%)\end{array}$ & $\pm 0,12$ & $\begin{array}{c}1,07 \\
(100 \%)\end{array}$ & $\pm 0,12$ & $\begin{array}{c}0,89 \\
(100 \%)\end{array}$ & $\pm 0,200$ \\
\hline 7 & $\begin{array}{c}0,90 \\
(97,8 \%)\end{array}$ & $\pm 0,02$ & $\begin{array}{c}0,89 \\
(83,2 \%)\end{array}$ & $\pm 0,20$ & $\begin{array}{c}0,82 \\
(92,1 \%)\end{array}$ & $\pm 0,075$ \\
\hline 14 & $\begin{array}{c}0,89 \\
(96,7 \%)\end{array}$ & $\pm 0,20$ & $\begin{array}{c}0,76 \\
(71,0 \%)\end{array}$ & $\pm 0,05$ & $\begin{array}{c}0,72 \\
(80,9 \%)\end{array}$ & $\pm 0,110$ \\
\hline 21 & $\begin{array}{c}0,74 \\
(80,4 \%)\end{array}$ & $\pm 0,06$ & $\begin{array}{c}0,63 \\
(58,9 \%)\end{array}$ & $\pm 0,14$ & $\begin{array}{c}0,64 \\
(71,9 \%)\end{array}$ & $\pm 0,170$ \\
\hline 28 & $\begin{array}{c}0,73 \\
(79,3 \%)\end{array}$ & $\pm 0,05$ & $\begin{array}{c}0,50 \\
(46,7 \%)\end{array}$ & $\pm 0,06$ & $(-1)$ & $(-)$ \\
\hline 35 & $\begin{array}{c}0,53 \\
(56,6 \%)\end{array}$ & $\pm 0,05$ & $(-1)$ & $(-)$ & $(-1)$ & $(-)$ \\
\hline
\end{tabular}

A atividade da polifenoloxidase (PPO) apresentou pequenas variações durante o armazenamento nas três temperaturas (Tabela 3). De um modo geral pode-se observar um decréscimo no final do armazenamento.

TABELA 3 - Valores médios de polifenoloxidase (unid. min $.100 \mathrm{~mL}$ ) de uvas "Niágara Rosada", cultivadas no sistema orgânico e armazenadas a $1^{\circ} \mathrm{C}, 14^{\circ} \mathrm{C}$ e $24^{\circ} \mathrm{C}$, durante 35,28 e 21 dias, respectivamente

\begin{tabular}{ccccccc}
\hline & \multicolumn{9}{c}{ Temperatura de armazenamento $\left({ }^{\circ} \mathrm{C}\right)$} \\
\hline $\begin{array}{c}\text { Periodo de } \\
\text { armazenamento } \\
\text { (Dias) }\end{array}$ & \multicolumn{2}{c}{$1^{\circ} \mathrm{C}$} & \multicolumn{3}{c}{$14^{\circ} \mathrm{C}$} & \multicolumn{2}{c}{$24^{\circ} \mathrm{C}$} \\
\hline 0 & 15,91 & $\pm 0,48$ & 16,24 & $\pm 0,45$ & 16,24 & $\pm 0,45$ \\
7 & 15,08 & $\pm 0,19$ & 15,98 & $\pm 0,19$ & 16,67 & $\pm 0,25$ \\
14 & 16,40 & $\pm 0,16$ & 17,00 & $\pm 0,22$ & 16,71 & $\pm 0,24$ \\
21 & 17,26 & $\pm 0,21$ & 15,84 & $\pm 0,37$ & 14,33 & $\pm 0,27$ \\
28 & 17,11 & $\pm 0,30$ & 15,51 & $\pm 0,31$ & $(-)$ & $(-)$ \\
35 & 16,93 & $\pm 0,19$ & $(-)$ & $(-)$ & $(-)$ & $(-)$ \\
\hline 3 repetiç̄es & & & & & &
\end{tabular}

$\delta=$ Desvio padrão

Sabe-se que a uva possui elevada atividade da enzima polifenoloxidase e o escurecimento enzimático ocorre rapidamente em bagas danificadas. Esta reação causa uma mudança radical na cor e aroma do suco e conseqüentemente diminui a qualidade do produto final [27].

O escurecimento é geralmente devido à ação catalítica da enzima polifenoloxidase [21], a qual na presença de oxigênio, provoca a oxidação de o-difenóis, presente nos tecidos das frutas. Esta reação de oxidação resulta na produção de o-quinonas, produzindo pigmentos marrons [30].

Alterações no conteúdo destas enzimas podem ocorrer durante o armazenamento. De acordo com CENCI [8] o aumento na atividade da PPO e POD durante o armazenamento de uva pode estar associado à senescência dos tecidos das bagas, o que envolve aumento na atividade da peroxidase, prejudicando a qualidade da fruta.

Na Tabela 4 pode-se observar que a atividade da peroxidase diminuiu ao final do armazenamento nas três temperaturas. Este dado está de acordo ao verificado por CENCI [8] em uvas "Niágara Rosada" submetidas ao ar- 
mazenamento refrigerado, as quais também apresentaram queda no final do armazenamento.

TABELA 4 - Valores médios de peroxidase (unid.min '.100mL ) de uvas "Niágara Rosada", cultivadas no sistema orgânico e armazenadas a $1^{\circ} \mathrm{C}, 14^{\circ} \mathrm{C}$ e $24^{\circ} \mathrm{C}$, durante 35,28 e 21 dias, respectivamente

\begin{tabular}{|c|c|c|c|c|c|c|}
\hline \multirow{3}{*}{$\begin{array}{c}\text { Periodo de } \\
\text { armazenamento } \\
\text { (Dias) }\end{array}$} & \multicolumn{6}{|c|}{ Temperatura de armazenamento $\left({ }^{\circ} \mathrm{C}\right)$} \\
\hline & \multicolumn{2}{|c|}{$1^{\circ} \mathrm{C}$} & \multicolumn{2}{|c|}{$14^{\circ} \mathrm{C}$} & \multicolumn{2}{|c|}{$24^{\circ} \mathrm{C}$} \\
\hline & $\mathrm{POD}^{\star}$ & $\delta$ & $\mathrm{POD}^{*}$ & $\delta$ & $\mathrm{POD}^{*}$ & 8 \\
\hline 0 & 115,00 & $\pm 4,08$ & 115,00 & $\pm 4,08$ & 115,00 & $\pm 4,08$ \\
\hline 7 & 75,00 & $\pm 4,08$ & 65,00 & $\pm 4,08$ & 110,00 & $\pm 4,08$ \\
\hline 14 & 85,00 & $\pm 4,08$ & 103,33 & $\pm 2,36$ & 106,67 & $\pm 6,24$ \\
\hline 21 & 95,00 & $\pm 8,16$ & 96,67 & $\pm 6,24$ & 80,00 & $\pm 0,00$ \\
\hline 28 & 101,67 & $\pm 6,24$ & 78,33 & $\pm 6,24$ & $(-1)$ & $(-)$ \\
\hline 35 & 76,67 & $\pm 6,24$ & $(-)$ & $(-)$ & $(-1)$ & $(-)$ \\
\hline
\end{tabular}

A temperatura de $24^{\circ} \mathrm{C}$ provavelmente favoreceu a atividade desta enzima, pois segundo relatos de CALDERÓN et al. [4] pode ocorrer mudança na atividade da peroxidase em função de estresses, mudanças na ontogenia, características específicas da cultivar.

No armazenamento a $24^{\circ} \mathrm{C}$, também foi observado queda no teor de vitamina $\mathrm{C}$, de acordo com CLEMENTE [10] a peroxidase pode catalisar a oxidação de vitaminas, além de compostos aromáticos e substâncias reguladoras de crescimento.

Neste experimento foram utilizados frutos coletados somente em uma safra, portanto as informações obtidas mostram apenas uma tendência de comportamento da uva orgânica durante o armazenamento a $1^{\circ} \mathrm{C}, 14^{\circ} \mathrm{C}$ e $24^{\circ} \mathrm{C}$. Diante disso destaca-se a importância da realização de estudos complementares bem como a realização destas avaliações em safras posteriores.

\section{4 - CONCLUSÕES}

Através das determinações físicas pode-se observar que a temperatura de $1^{\circ} \mathrm{C}$ proporcionou menor índice de degrana do cacho, promovendo maior periodo de armazenamento em relação às demais temperaturas utilizadas.

Os teores de sólidos solúveis totais e a acidez total titulável não apresentaram decréscimos durante o armazenamento a 1 e $14^{\circ} \mathrm{C}$, porém quando submetidos a $24^{\circ} \mathrm{C}$ ocorreu diminuição nos teores de SST e ATT durante o armazenamento. A vitamina $\mathrm{C}$ diminuiu durante o armazenamento nas três temperaturas.

A polifenoloxidase e a peroxidase apresentaram diminuição da atividade no final do armazenamento, apesar de ter ocorrido diminuição na atividade destas enzimas, estas ainda se apresentaram ativas até o final do periodo de armazenamento.

\section{5 - REFERÊNCIAS BIBLIOGRÁFICAS}

[1] AL KAISY, A. M.; SACHDE, A.G.; GHALIB, H.A.;HAMEL, S.M. Physical and chemical changes during ripening of some grape varieties grown in Basrah. Amercian Journal of Enology and Viticulture, v.32, n.4, p.268271, 1981.

[2] AOAC Association of Oficial Agriculture Chemists. Official Methods of Analysis of the Association of the Agricultural Chemistry. 11.ed. Washington, 1992.

[3] BRACKMANN, A.; MAZARO, S. M.; WACLAWOVSKY, A. $\mathrm{J}$. Armazenamento refrigerado de uvas cvs. Tardia de Caxias e Dona Zilá. Ciência Rural, v. 30, n. 4, p. 581$586,2000$.

[4] CALDERÓN, A.A.; ZAPATA, J.M.; MUÑOZ, R.; ROS BARCELÓ, A. Localization of peroxidase in grapes using nitrocellulose blotting of freezing thawing fruits. HortScience. v. 28, n. 1, p. 38-40, 1993.

[5] CAMARGO, U. A. Cultivares para a viticultura tropical no Brasil. Informe Agropecuário, v. 19, n. 194, p. 14-19, 1998.

[6] CARDELlO, H. M. A. B.; CARDELLO, L. Teor de vitamina $\mathrm{C}$, atividade de ascorbato oxidase e perfil sensorial de manga (Mangifera indica L.) var. Haden, durante o amadurecimento. Ciênc. Tecnol. Aliment., v. 18, n. 2, p. 211-217, 1998.

[7] CASTRO, J. V. de. Resfriamento, embalagens e uso de dióxido de enxofre na conservação e na qualidade de uvas (Vitis vinifera L.) 'Itália' e 'Red Globe'. Campinas, 1999, 109 p. Tese (Doutorado em Engenharia Agrícola), Faculdade de Engenharia Agrícola, Universidade Estadual de Campinas (UNICAMP).

[8] CENCI, S. A. Ácido naftalenoacético (ANA) e cloreto de cálcio na pré-colheita de uva niágara rosada (Vitis labrusca L. X Vitis vinifera L.): avaliação do potencial de conservação no armazenamento. Lavras, 1994, 109 p. Tese (Doutorado em Ciência dos Alimentos), Escola Superior de Agricultura de Lavras.

[9] CHITARRA, M.I.F.; CHITARRA, A.B. Pós-colheita de frutos e hortaliças: fisiologia e manuseio. Lavras: ESAL/FAEPE, 1990.

[10] CLEMENTE, E. The characterisation of peroxidase from oranges. Leeds, 1993, 202p. PhD Tesis (Procter Department of Food Science), University of Leeds.

[11] CLEMENTE, E. Peroxidase from oranges (Citrus sinenses (L.) Osbeck). European Food Research and Technology, v. 215, n. 2, p. 164-168, 2002.

[12] COOMBE, B.G. Research on development and ripening of the grape berry. American Journal of Enology and Viticulture, v. 43, n. 1, p. 101-110, 1992.

[13] DONAZZOLO, J.; BRACKMANN, A.; WACLAWOVSKY, A. J. Armazenamento refrigerado de uvas cv. Isabel. In: CONGRESSO BRASILEIRO DE VITICULTURA E ENOLOGIA, 9, 1999, Bento Gonçalves: Embrapa Uva e Vinho, 1999.

[14] FERREIRA, E. A. Antecipação de safra da videira cultivar niágara rosada (Vitis labrusca $L$. $x$ Vitis vinifera L.) no sul de Minas Gerais. Lavras, 2000, 66 p. Dissertação (Mestrado em Fitotecnia), Universidade Federal de Lavras (UFLA).

[15] FLORES-CANTILLANO, R. F.; MADAIL, J. C. M.; MATTOS, M. L. T. Mercado de alimentos: tendência mundial. Informe Agropecuário, v. 22, n. 213, p. 79-84, 
2001.

[16] GOMES, F. P. Curso de estatística experimental. 13. ed. Piracicaba: Nobel, 1990.

[17] GRANGEIRO, L. C.; SOARES, J. M.; REIS, C. dos S.; DI GALVANINI, F.; SILVA, A. V. C. da. Armazenamento refrigerado de uva, cultivar Superior Seedless produzida no Vale do São Francisco. In: CONGRESSO BRASILEIRO DE FRUTICULTURA, 2002. Anais... Belém, 2002.

[18] INSTITUTO DE TECNOLOGIA DE ALIMENTOS. Manual técnico de análise química de alimentos. Campinas, 1990.

[19] JANOVITZ-KLAPP, A.; RICHARD, F.; NICOLAS, J. Polyphenoloxidase from apple, partial purification and some properties. Phytochemistry. v. 28, n. 11, p. 29032907, 1989.

[20] LEÃO, P. C. de S. Principais variedades. In: LEÃO, P. C. de S.; SOARES, J. M. (Coords.) A Viticultura no semiárido brasileiro. Petrolina: Embrapa Semi-Árido, 2000. Cap. 4, p. 45-64.

[21] LIMA, M. A. C. de; ALVES, R. E.; ASSIS, J. S. de; FILGUEIRAS, H. A. C.; COSTA, J. T. A. Qualidade, fenóis e enzimas oxidativas de uva 'Itália' sob influência do cálcio, durante a maturação. Pesquisa Agropecuária Brasileira, Brasília, v. 35 , n. 12, p. 2493-2499, dez. 2000.

[22] LuQueta, N.M.; LAgEMANN, T.M.I. Conhecendo Toledo: Geografia e História. Secretaria Municipal da Educação. Toledo: Sul Gráfica, 1999.

[23] ORLANDO, T. das G. S. Características ecofisiológicas de cultivares de videira em diferentes sistemas de condução. Lavras, 2002, 126 p. Tese (Doutorado em Fitotecnia), Universidade Federal de Lavras (UFLA).

[24] RUFFNER, H. P.; BREM, S.; MALIPIERO, U. The physiology of acid metabolism in grape berry ripening.
Acta Horticulturae, v. 139, p. 123-128, 1983.

[25] UNIVERSIDAdE FEDERAL DE VIÇOSA. Manual de utilização do programa SAEG (Sistema para análises estatísticas e genéticas). Viçosa: UFV, 1999.

[26] VALENTINI, S. R. de T. MIQUELETTO, D. F. Conservação de uva 'Niágara' (Vitis labrusca) em diferentes embalagens e condições de armazenamento. In: CONGRESSO BRASILEIRO DE VITICULTURA E ENOLOGIA e SEMINáRIO CYTED, 10, 2003, Bento Gonçalves: Embrapa Uva e Vinho, 2003. p 204.

[27] VALERO, E.; VARÓN, R.; GARCÍA-CARMONA, F. Characterisation of polyphenoloxidase from Airen grapes. Journal of Food Science. v. 53, n. 5, 1988.

[28] WILlS, R.; McGlaSS, B.; GRAHAM, D.; JOYCE, D. Introducción a la fisiologia y manipulación poscosecha de frutas, hortalizas y plantas ornamentales. Tradução: GONZÁLEZ, J.B. 2 edición. Zaragoza: Acribia S.A., 1998.

[29] WEEMAES, C.A ; LUDIKHUYZE, L.R.; VAN DEN BROECK, I.; HENDRICHX, M.E.; TOBBACK, P.P. Activity, eletrophoretic characteristics and heat inactivation of polyphenoloxidases from apples, avocados, grapes, pears and plums. Technology. Lebensm-Wiss, v. 31, p. 44-49, 1998.

[30] YAMASHITA, F.; TONZAR, A. C.; FERNÁNDEZ, J. G.; MORIYA, S.; BENASSI, M. De T. Influencia de diferentes embalagens de atmosfera modificada sobre a aceitação de uvas finas de mesa var. Itália mantidas sob refrigeração. Ciênc. Tecnol. Aliment. Vol. 20, n. 1. Campinas, 2000.

\section{6 - AGRADECIMENTOS}

Agradecemos à CAPES pelo apoio financeiro e ao Sr.Carlinhos Fornari, proprietário do Sítio Beija-Flor, pelo fornecimento das uvas. 